\title{
Exploring Machinability of AISI 4340 Steel with Coated Carbide Inserts
}

\author{
S. Das ${ }^{1}$, S. Das ${ }^{2 *}$, B. Mandal ${ }^{3}$ \\ ${ }^{1,2,3}$ Kalyani Government Engineering College, Kalyani, West Bengal, India \\ \{sdas.me@gmail.com\}
}

\begin{abstract}
Turning is widely employed as a material removal process for roughing or semi-finishing operation. However, turning of a workpiece material needs use of an appropriate cutting tool insert. Insert material and its geometry play quite significant role in obtaining desired machinability. For obtaining better finish of machined surface, nose radius also plays an important role. In the present work, two coated carbide cutting tool inserts with two different nose radii of $1.2 \mathrm{~mm}$ and $1.6 \mathrm{~mm}$ are used under two cutting velocity and four feed of low values to explore machinability of AISI 4340 steel during turning in dry condition. Type of chip formation, cutting forces required, etc. are noted during the experiment. The condition corresponding to good machinability is finally recommended.
\end{abstract}

Keywords: machining, turning, machinability, carbide insert, cutting force

\section{Introduction}

Material and geometry of a tool insert play vital role to have desired machinability under appropriate machining conditions. Different researchers carried out investigations to explore machinability corresponding to a workpiece-cutting tool combination. Different optimisation algorithms were also tried [1-7] to find out appropriate machining parameters. This author and his team explored turning experiments consuming less energy [8] and also the performance of a newly developed CNT-reinforced alumina tool insert [9].

Yanda et al. [10] found out the effect of cutting conditions in dry environment on material removal rate, surface roughness and tool life while turning ductile cast iron rods using TiN coated cutting tool, while Mondal et al. [11] explored machinability during turning a hard material. Ramanujam et al. [12] selected optimal machining parameters in $\mathrm{Al}-15 \% \mathrm{SiCp}$ metal matrix composites. Selvaraj and Chandarmohan [13] reported the influence of basic cutting parameters on surface roughness of austenitic stainless steel rods during dry turning with the use of $\mathrm{TiC}$ and TiCN coated tungsten carbide cutting tool. Sahoo et al. [14] developed mathematical models and did parametric optimization for surface roughness in turning D2 steel using TiN coated carbide insert. Velibor and Milos [15] employed Taguchi robust parameter design for modeling and optimization of surface roughness in dry single-point turning of cold rolled alloy steel using TiN-coated tungsten carbide inserts, when Kazancoglu et al. [16] investigated turning process for evaluating an optimal parametric combination to require quite low cutting forces, and to yield quite low surface roughness with maximum material removal rate (MRR) using a combination of a Grey relational analysis (GRA) and the Taguchi method. Verma et al. [17] also derived through Taguchi method optimal cutting condition to obtain appreciably low surface roughness in turning ASTM A242 Type-1 alloy steel. The effect of cutting parameters and workpiece hardness on surface roughness and cutting force components in hard turning of AISI H11 steel was investigated by Aouici et al. [18] using cubic boron nitride. Yadav et al. [19] evaluated the relation between the change in hardness of EN 8 workpiece during turning with varying machining parameters. The same workpiece material was also machined by Vikas and Vinayak [20] to find out appropriate machining parameters. Biswas and Mandal [21], in an investigation, modeled turning process parameters to reduce frequency of tool vibration and tool wear rate substantially. Models were further optimized using Genetic Algorithm. EN-31 steel workpiece and carbide insert were used by them.

B. Iyer, S. Nalbalwar and R. Pawade (Eds.)

ICCASP/ICMMD-2016. Advances in Intelligent Systems Research.

Vol. 137, Pp. 165-170.

(C) 2017. The authors - Published by Atlantis Press

This is an open access article under the CC BY-NC license (http://creativecommons.org/licens)es/by-nc/4.0/). 
Two types of coated carbide inserts with two different nose radii of $1.2 \mathrm{~mm}$ and $1.6 \mathrm{~mm}$ are used in the present work under two cutting velocity and four feed to explore machinability of AISI 4340 steel during turning in dry condition. Type of chip formation, cutting forces required, etc. are noted during the experiment. The aim is to recommend suitable parametric combination corresponding to good machinability.

\section{Experimental Details}

Turning tests are performed on a Mysore Kirloskar Ltd., Bangalore made centre lathe (model: Turnmaster, TM35; main motor power: $2.2 \mathrm{~kW}$ ) to turn AISI 4340 steel rod. Composition of AISI 4340 steel is given in Table 1. Its hardness is 25 HRC. For measuring chip thickness, Mitutoyo, Japan make point-edge micrometer is used. Chip reduction coefficient (CRC) is found out with chip thickness and uncut chip thickness. Tool holder (R174.3- 2020-12) used is made by Sandvik Asia Ltd., India having tool signature, $-6^{\circ},-6^{\circ}, 6^{\circ}, 6^{\circ}, 15^{\circ}, 75^{\circ}$ and two nose radii of $1.2 \mathrm{~mm}$ and $1.6 \mathrm{~mm}$. Sandvik Asia Ltd., India made carbide tool inserts are used having specification: SNMG 120412-PF and SNMG 120416-PR. Photographs of these two inserts are shown in Fig. 1. Experimental detail is shown in Table 2.
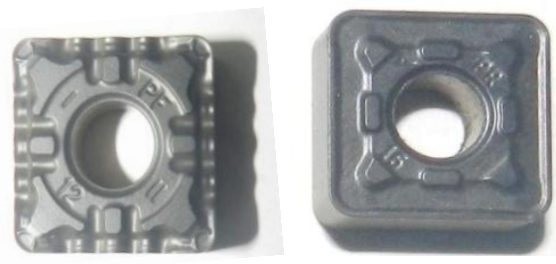

Fig. 1. Photograph of inserts used

Table 1 Chemical composition of AISI 4340 steel used

\begin{tabular}{|l|l|l|l|l|l|l|l|}
\hline C 0.14\% & Si 0.56\% & Mn 1.29\% & P 0.036\% & S 0.036\% & Cr 1.101\% & Ni 0.087\% & Al 0.037\% \\
\hline Co 0.017\% & Cu 0.137\% & Nb 0.005\% & V 0.011\% & W 0.085\% & Pb 0.013\% & Sn 0.01\% & As 0.053\% \\
\hline
\end{tabular}

Table 2 Experimental Condition

\begin{tabular}{|c|c|c|c|c|c|}
\hline Experiment set & $\begin{array}{c}\text { Cutting velocity, } \\
\mathrm{V}_{\mathrm{c}}(\mathrm{m} / \mathrm{min})\end{array}$ & $\begin{array}{c}\text { Feed, } \mathrm{f} \\
(\mathrm{mm} / \mathrm{rev})\end{array}$ & $\begin{array}{c}\text { Depth of cut, } \\
\mathrm{t}(\mathrm{mm})\end{array}$ & $\begin{array}{c}\text { Nose radius, } \\
\mathrm{r}(\mathrm{mm})\end{array}$ & $\begin{array}{c}\text { Environmen } \\
\mathrm{t}\end{array}$ \\
\cline { 1 - 2 } & \multirow{2}{*}{93,147} & $0.112,0.09,0.071,0.05$ & 1 & 1.2 & Dry \\
\cline { 1 - 1 } & & & 1.6 & \\
\hline
\end{tabular}

\section{Results and Discussion}

In this investigation, values of chip reduction coefficient (CRC) are calculated, and types of chip formed and formation of built-up edge are observed. Main cutting force and horizontal cutting force components are noted. Results obtained from experiments performed as detailed in Table 2 are presented, and discussion on them are detailed corresponding to the two sets of experiments.

\subsection{Observation and discussion on results of experiment set 1}

Experiment set 1 is performed on AISI 4340 rod using TiC coated carbide tool insert of $1.2 \mathrm{~mm}$ nose radius. Results obtained from experiment set 1 are shown in Table 3, and Figs. 2-4. No built-up edge is found in this set of experiment. CRC varies from 1.19-2.29. Mostly chips are coiled type continuous and a few chips are irregular or ribbon type continuous. 
Table 3 Experimental data in turning AISI 4340 steel with $1.2 \mathrm{~mm}$ nose radius in experiment set 1

\begin{tabular}{|c|c|c|c|c|c|c|c|c|}
\hline $\begin{array}{l}\dot{0} \\
\dot{z} \\
\dot{n}\end{array}$ & 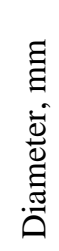 & 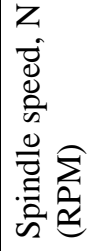 & 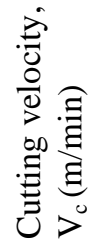 & 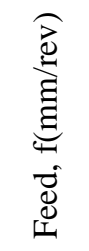 & 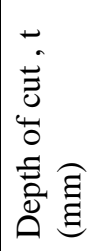 & 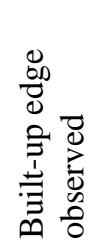 & 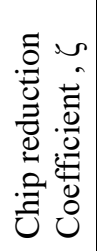 & 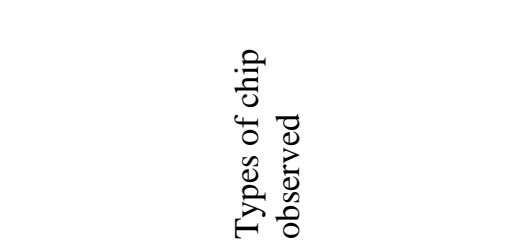 \\
\hline 1 & \multirow{8}{*}{66} & \multirow{4}{*}{450} & \multirow{4}{*}{93} & $\begin{array}{c}0.11 \\
2\end{array}$ & \multirow{8}{*}{1} & No & 1.48 & Open coil continuous, blue colour \\
\hline 2 & & & & 0.09 & & No & 2.29 & Open coil continuous, blue colour \\
\hline 3 & & & & $\begin{array}{c}0.07 \\
1\end{array}$ & & No & 1.97 & Open coil continuous, blue colour \\
\hline 4 & & & & 0.05 & & No & 1.87 & Open coil continuous, blue colour \\
\hline 5 & & \multirow{4}{*}{710} & \multirow{4}{*}{147} & $\begin{array}{c}0.11 \\
2\end{array}$ & & No & 1.29 & Ribbon type continuous, blue colour \\
\hline 6 & & & & 0.09 & & No & 1.19 & Open coil continuous, blue colour \\
\hline 7 & & & & $\begin{array}{c}0.07 \\
1\end{array}$ & & No & 1.32 & Open coil continuous, blue colour \\
\hline 8 & & & & 0.05 & & No & 1.66 & Ribbon type continuous, blue colour \\
\hline
\end{tabular}

Variation of main cutting force and horizontal cutting force with feed are plotted in Fig. 3 and Fig. 4 respectively. Main force component $\left(\mathrm{P}_{\mathrm{z}}\right)$ has its range from $55.3 \mathrm{~N}$ to $122.2 \mathrm{~N}$. At $147 \mathrm{~m} / \mathrm{min}$ cutting velocity, $\mathrm{Vc}$ and $0.05 \mathrm{~mm} / \mathrm{rev}$ feed, low cutting force is observed that is desired. At this condition, flat ribbon type chips are formed indicating favourable machinability condition. Force increases with increase in feed on the whole, but sometimes, rate of increase in force is less. Also, higher Vc shows lesser force components that may be due to thermal softening effect.

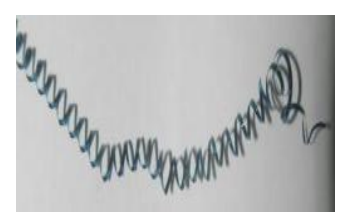

At $\mathrm{V}_{\mathrm{c}}=93 \mathrm{~m} / \mathrm{min}, \mathrm{f}=$ $0.112 \mathrm{~mm} / \mathrm{rev}, \mathrm{t}=1 \mathrm{~mm}$

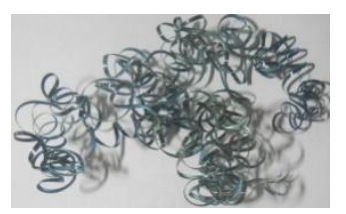

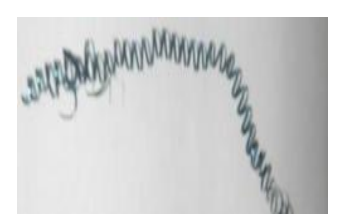

At $\mathrm{V}_{\mathrm{c}}=93 \mathrm{~m} / \mathrm{min}, \mathrm{f}=$ $0.09 \mathrm{~mm} / \mathrm{rev}, \mathrm{t}=1$ $\mathrm{mm}$

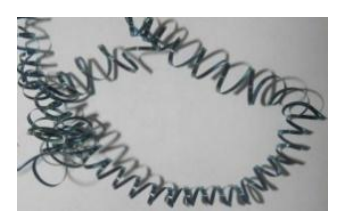

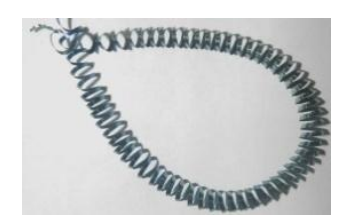

At $\mathrm{V}_{\mathrm{c}}=93 \mathrm{~m} / \mathrm{min}, \mathrm{f}=$ $0.071 \mathrm{~mm} / \mathrm{rev}, \mathrm{t}=1$ $\mathrm{mm}$

At $\mathrm{V}_{\mathrm{c}}=93 \mathrm{~m} / \mathrm{min}, \mathrm{f}=$ $0.05 \mathrm{~mm} / \mathrm{rev}, \mathrm{t}=1$ $\mathrm{mm}$

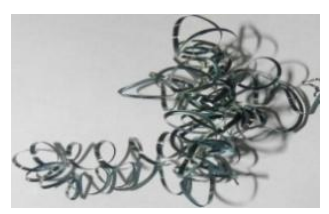

At $\mathrm{V}_{\mathrm{c}}=147 \mathrm{~m} / \mathrm{min}, \mathrm{f}=$

At $\mathrm{V}_{\mathrm{c}}=147 \mathrm{~m} / \mathrm{min}$, $\mathrm{f}=0.09 \mathrm{~mm} / \mathrm{rev}, \mathrm{t}=1$

At $\mathrm{V}_{\mathrm{c}}=147 \mathrm{~m} / \mathrm{min}$, At $\mathrm{V}_{\mathrm{c}}=147 \mathrm{~m} / \mathrm{min}$, $\mathrm{mm}$ $\mathrm{f}=0.071 \mathrm{~mm} / \mathrm{rev}, \mathrm{t}=$ $1 \mathrm{~mm}$ $\mathrm{f}=0.05 \mathrm{~mm} / \mathrm{rev}, \mathrm{t}=1$ $\mathrm{mm}$

Fig. 2. Photographs of observed chips in experiment set 1 with $1.2 \mathrm{~mm}$ nose radius 


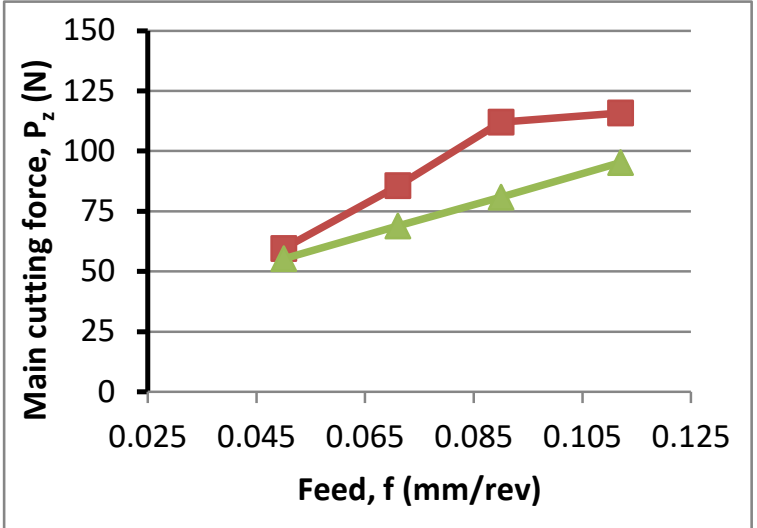

Fig. 3. Plot of variation of main cutting force with feed in experiment set 1 (red line is for $93 \mathrm{~m} / \mathrm{min} \mathrm{Vc}$, green line is for $\mathrm{Vc}=147 \mathrm{~m} / \mathrm{min}$ )

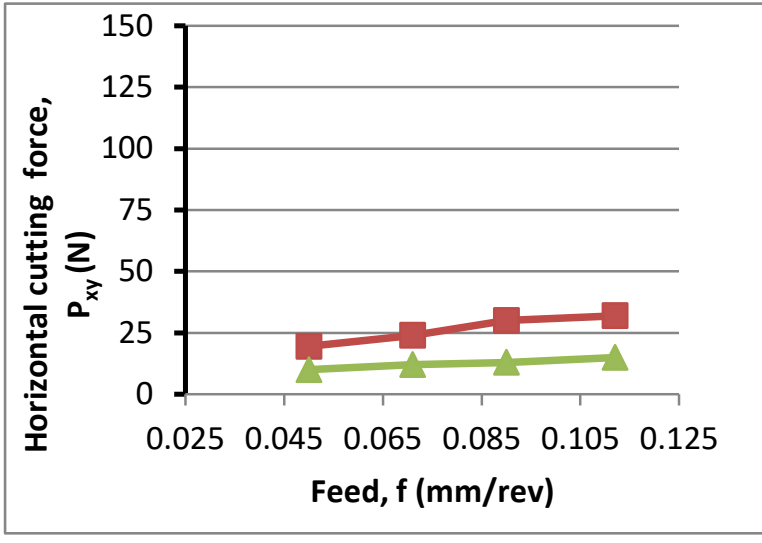

Fig. 4. Plot of variation of horizontal cutting force with feed in experiment set 1 (red line is for 93 $\mathrm{m} / \mathrm{min} \mathrm{Vc}$, green line is for $\mathrm{Vc}=147 \mathrm{~m} / \mathrm{min}$ )

\subsection{Observation and discussion on results of experiment set 2}

Experiment set 2 is performed with TiC coated carbide tool insert of $1.6 \mathrm{~mm}$ nose radius. Results obtained from experiment set 2 are shown in Table 4. This table includes CRC values ranging from 1.32 to 2.08. Types of chips observed are listed in Table 5 and their photographs are shown in Fig. 5. It is observed that mostly chips are coiled type continuous and only one or two chips are ribbon to irregular type continuous. Coil type chips require more force for its curling, and hence, the increased force values. No built-up edge is found in this set of experiment as observed in experiment set 1 also.

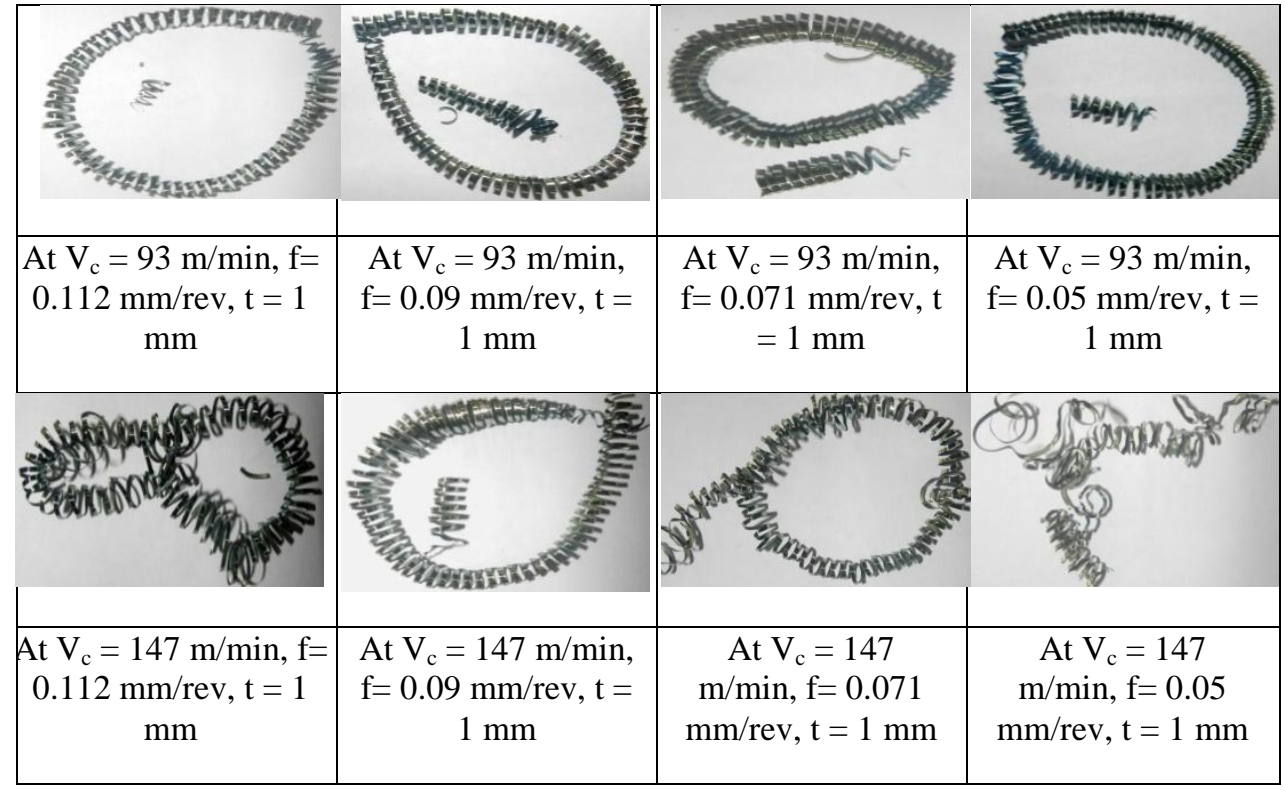

Fig. 5. Photographs of observed chips for experiment set 2 with $1.6 \mathrm{~mm}$ nose radius

Variation in main and horizontal cutting forces with feed at two cutting velocity are shown in Fig. 6 and Fig. 7 respectively. Main cutting force shows an increasing trend with an increase in feed at both the two cutting velocities. This trend is all but natural as increase in feed results in increased shear area that needs more shear force for deformation of enhanced shear area. However, this clear trend is not that prominent in case of horizontal cutting force (Fig. 7). Range of $\mathrm{P}_{\mathrm{z}}$ force is from $55.3 \mathrm{~N}$ to $115.8 \mathrm{~N}$. At $147 \mathrm{~m} / \mathrm{min}$ Vc and $0.05 \mathrm{~mm} / \mathrm{rev}$ feed, low cutting force is observed that is desired. At this experiment set 2, clear effect of cutting velocity on force components is not visible. However, it is seen by comparing the force results of $1.2 \mathrm{~mm}$ and $1.6 \mathrm{~mm}$ nose radius inserts that increase in nose radius tends to require more forces as a natural phenomenon. 


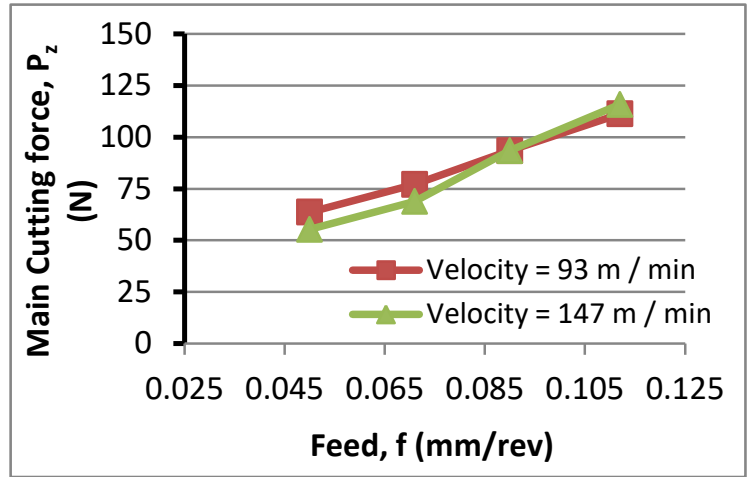

Fig. 6. Plot of variation of main cutting force with feed in experiment set 2

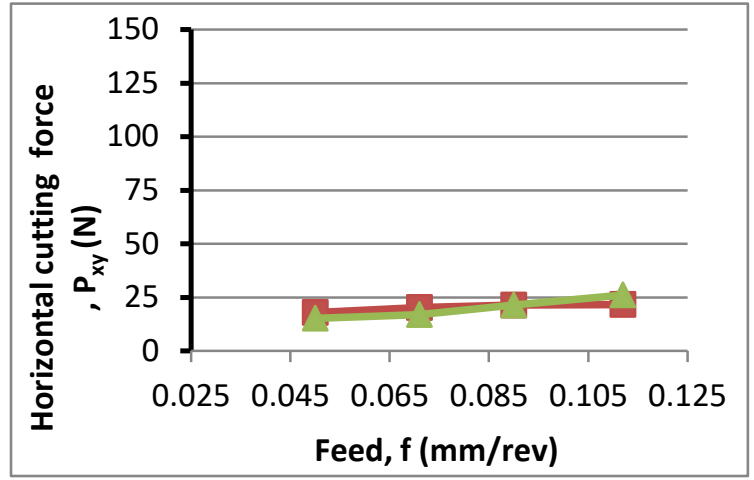

Fig. 7. Plot of variation of horizontal cutting force with feed in experiment set 2

Table 4 Experimental data obtained with $1.6 \mathrm{~mm}$ nose radius in experiment Set 2

\begin{tabular}{|c|c|c|c|c|c|c|c|c|}
\hline $\begin{array}{l}\dot{z} \\
\dot{n}\end{array}$ & 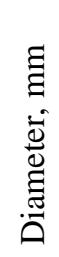 & 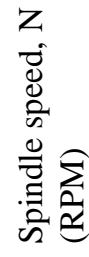 & 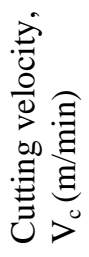 & 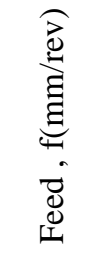 & 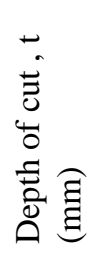 & 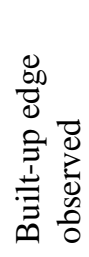 & 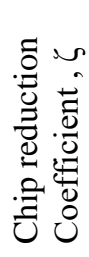 & 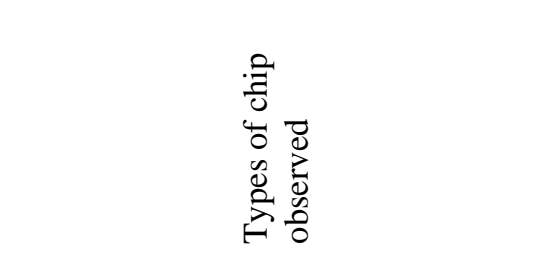 \\
\hline 1 & \multirow{8}{*}{66} & \multirow{4}{*}{450} & \multirow{4}{*}{93} & 0.112 & \multirow{8}{*}{1} & No & 1.38 & Open coil continuous, blue colour \\
\hline 2 & & & & 0.09 & & No & 1.49 & Open coil continuous, blue colour \\
\hline 3 & & & & 0.071 & & No & 1.61 & Open coil continuous, blue colour \\
\hline 4 & & & & 0.05 & & No & 2.08 & $\begin{array}{l}\text { Open coil continuous and some ribbon } \\
\text { type, blue colour }\end{array}$ \\
\hline 5 & & \multirow{4}{*}{710} & \multirow{4}{*}{147} & 0.112 & & No & 1.48 & Open coil continuous, blue colour \\
\hline 6 & & & & 0.09 & & No & 1.49 & Open coil continuous, blue colour \\
\hline 7 & & & & 0.071 & & No & 1.32 & Open coil continuous, blue colour \\
\hline 8 & & & & 0.05 & & No & 1.66 & Ribbon type continuous, blue colour, \\
\hline
\end{tabular}

\section{Conclusions}

Following are conclusions drawn from the results obtained from the experiments performed.

1. Fairly good machinability is obtained with the two inserts at all the machining conditions chosen.

2. Favourable chip formation that is generation of flat continuous chips is obtained with $1.2 \mathrm{~mm}$ nose radius at a cutting velocity of $147 \mathrm{~m} / \mathrm{min}$ at a feed of $0.05 \mathrm{~mm} / \mathrm{rev}$. At this condition, cutting forces are on the whole less compared to other conditions. Hence, this condition may be recommended to yield good machinability.

\section{Acknowledgement}

Authors wish to acknowledge the help and support of Mr. Goutam Chakraborty and Sushanta Halder of Machine Shop towards conduct of the experiments.

\section{References}

[1] C. Su and M. C. Chen, "Computer-aided optimization of multi-pass turning operations for continuous forms on CNC lathes", IIE Transactions, 31 (1999) 583-596.

[2] U. Zuperl and F. Cus, "Optimization of cutting conditions during machining by using neural networks", The proceedings International Conference on Flexible Automation and Intelligent Manufacturing, Dresden, Germany, (2012) 1-11. 
[3] H. Singh and P. Kumar, "Tool wear optimization in turning operation by Taguchi method", Indian Journal of Engineering \& Materials Sciences, 11 (2004) 19-24.

[4] E.D. Kirby, "A parameter design study in a turning operation using the taguchi method", The Technology Interface, Fall 2006.

[5] M. Nalbant, H. Gokkaya and G. Sur, "Application of Taguchi method in the optimization of cutting parameters for surface roughness in turning", Materials and Design, 28 (2007) 379-1385.

[6] R.V. Rao and V.D. Kalyankar, "Multi-pass turning process parameter optimization using teaching-learning-based optimization algorithm", Scientia Iranica, 20(3) (2013) 967-974.

[7] B.M. Gopalsamy, B. Mondal and S. Ghosh, "An approach for process parameters optimization of hard machining while machining hardened steel by Taguchi method and ANOVA analysis", Journal of Scientific \& Industrial Research, 68 (2009) 686-695.

[8] A. Bhattacharya, S. Das, P. Majumder and A. Batish, "Estimating the Effect of Cutting Parameters on Surface Finish and Power Consumption during High Speed Machining of AISI 1045 Steel Using Taguchi Design and ANOVA", Production Engineering: Research and Development, 3 (2009) 31-40.

[9] S. Sarkar, S. Sarkar, P.K. Das, S. Das and S. Paul, "Performance of a newly developed carbon nanotube reinforced alumina tool insert during turning of AISI 1060 steel", Journal of the Association of Engineers, India, 86(1\&2) (2016) 64-79.

[10] H. Yanda, J.A. Ghani, M.N.A.M. Rodzi, K. Othman and C.H.C. Haron, "Optimization of material removal rate, surface roughness and tool life on conventional dry turning of FCD700", International Journal of Mechanical and Materials Engineering, 5 (2010) 182-190.

[11] K. Mondal, S. Das, B. Mandal and D. Sarkar, An investigation on turning hardened steel using different tool inserts, Materials and Manufacturing Processes, 31(13) (2016) 1770-1781.

[12] R. Ramanujam, R. Raju and N. Muthukrishnan, "Taguchi multi-machining characteristics optimization in turning of Al-15\% SiCp composites using desirability function analysis", Journal of studies on Manufacturing, 1 (2010) 120-125.

[13] D.P. Selvaraj and P. Chandramohan, "Optimization of surface roughness of AISI 304 austenitic stainless steel in dry turning operation using Taguchi design method", Journal of Engineering Science and Technology, 5 (2010) 293-301.

[14] P. Sahoo, "Optimization of turning parameters for surface roughness using RSM and GA", Advances in Production Engineering \& Management, 3 (2011) 197-208.

[15] M. Velibor and M. Milos, "Optimization of surface roughness in turning alloy steel by using Taguchi method”, Scientific Research and Essays, 6 (2011) 3474 -3484.

[16] Y. Kazancoglu, U. Esme, M. Bayramoglu, O. Guven and S. Ozgun, "Multi-objective optimization of the cutting forces in turning operations using the grey-based Taguchi method", Original Scientific Article, 45 (2011) 105-110.

[17] J. Verma, P. Agrawal and L. Bajpai, "Turning parameter optimization for surface roughness of ASTM A242 type-1 alloys steel by Taguchi method", International Journal of Advances in Engineering \& Technology, 3 (2012) 255-261.

[18] H. Aouici, M.A. Yallese and K. Chaoui, "Analysis of surface roughness and cutting force components in hard turning with CBN tool: prediction model and cutting conditions optimization", Measurement, 45 (2012) 344-353.

[19] A. Yadav, A. Bangar, R. Sharma and D. Pal, "Optimization of turning process parameters for their effect on EN 8 material work piece hardness by using Taguchi parametric optimization method", International Journal of Mechanical and Industrial Engineering, 1 (2012) 36-40.

[20] B. Vikas and R. Vinayak, "Evaluation and optimization of machining parameter for turning of EN 8 steel”, International Journal of Engineering Trends and Technology, 4 (2013) 1564-1568.

[21] A. Biswas and N.K. Mandal, "Multi-objective optimization of chatter vibration and flank wear of EN-32 steel in CNC turning", The SciTech International Journal of Engineering Sciences, 2 (2014) 36-48. 